\title{
LOS DERECHOS HUMANOS DE LOS MIGRANTES EN ANGOLA: DOS AÑOS DESPUÉS DE LA VISITA DEL ENVIADO ESPECIAL DE LA ONU
}

\author{
The human rights of migrants in Angola: two years after the visit \\ of the UN special observer
}

Avelino Chico*

\begin{abstract}
Resumen. Existe un creciente interés por los derechos humanos de los migrantes en Angola. No hace mucho que los angoleños abandonaban el país a causa de la guerra. Sin embargo, desde el final del conflicto, en 2002, el país ha sido objeto de enormes flujos de inmigrantes y refugiados. La estabilidad política y el crecimiento económico figura entre los factores de atracción. La crisis económica que el país afronta actualmente no está teniendo el impacto que se esperaba, pues los flujos migratorios no han cesado. Razón por la cual François Crépeau, relator especial de la ONU para los Derechos Humanos de los Migrantes, visitó el país. Al final de su estancia elaboró un informe que aborda la situación de los derechos humanos de los migrantes. Este artículo pretende analizarlo y resaltar que dos años tras su visita la situación sigue igual.
\end{abstract}

Palavras-chave: Angola; derechos humanos; inmigrantes; refugiados.

\begin{abstract}
There is growing interest in the human right of migrants in Angola. Not long ago, Angolans used to leave their country because of the war. Nevertheless, since the end of the conflict, in 2002, the country has seen the flows of immigrants and refugees. Political stability and economic growth are among the pull factors. Even the economic crisis, which is actually affecting the country, has stopped the flows of migrants. For this reason, François Crépeau, the UN special rapporteur on the human rights of migrants, visited the country. At the end of his stay, he wrote a report on the human rights of migrants. This article intends to analyze it and emphasize that, two years after his visit, the situation remains the same.
\end{abstract}

Keywords: Angola; human rights; immigrants; refugees.

Doutoramento em migrações internacionais e cooperação para o desenvolvimento, Universidad Pontificia Comillas. Madrid, España. 


\section{Introducción}

François Crépeau, enviado especial de la Organización de las Naciones Unidas (ONU) para los derechos humanos de los migrantes, visitó Angola a invitación del gobierno local del 3 al 10 de mayo de 2016. El objetivo del mandatario de la ONU consistió en evaluar la situación de los derechos humanos de los migrantes ${ }^{1}$, así como las políticas y leyes migratorias del país. Además de las autoridades gubernamentales, Crépeau se ha encontrado con representantes de la sociedad civil y las organizaciones internacionales. En modo destacado cabe señalar el encuentro que mantuvo con los representantes del Alto Comisionado de las Naciones Unidas para los Refugiados (ACNUR) y la Organización Internacional para las Migraciones (OIM) y con los propios migrantes. Al final de su visita, el observador de la ONU redactó un informe sobre lo que había constatado acerca de la situación de los derechos humanos de los migrantes.

Pasado un año, este trabajo consiste en analizar el informe que François Crépeau ha dejado tras la visita. Nuestro objetivo se propone mirar la realidad migratoria de Angola desde una perspectiva externa, en concreto, la que puede proporcionar un representante de una organización mundial con una misión específica. Al mismo tiempo se pretende una mirada desde dentro como ciudadano de esta nación. Las motivaciones personales nos mueven a tratar este tema con gran interés, ya que formábamos parte de las organizaciones con la que Crépeau se ha reunido. Se trata de la Comisión Episcopal de Migraciones (CEPAMI) creada por los obispos angoleños en 2006. Nuestra implicación contribuirá al enriquecimiento del estudio en la medida en que seamos capaces de integrar diversas perspectivas. Aparte de esta introducción, el artículo consta de cuatro partes: la primera parte comprende la presentación y análisis del informe; la segunda se centra en la valoración del informe; la tercera da una ojeada a la situación migratoria del país; y la cuarta está dedicada al resumen del trabajo. Al igual que Crépeau hablaremos de migrantes como categoría que incluye a inmigrantes, refugiados y requirentes de asilo.

\section{Pincelada histórica}

El informe empieza con una lectura histórica del país, marcado por las guerras y el escaso desarrollo económico y social del país. Con todo, esto ha cambiado en 2002 con el Acuerdo de Paz de Luena (Angola) entre los dos mayores movimientos armados en conflicto, el Movimiento Popular de Liberación de Angola (MPLA) y la Unión Nacional para la Independencia Total de Angola (UNITA). Hasta el día de hoy han pasado quince años de paz,

\footnotetext{
Con este término el informe también se refiere a los refugiados y solicitantes de asilo. Para acceder al informe: <http://www.pordentrodaafrica.com/wp-content/uploads/kalins-pdf/singles/angolaespecialista-da-onu-pede-estrategia-inclusiva-para-migrantes.pdf> . Acceso en: 04.06.2018.
} 
estabilidad y desarrollo económico. Este hecho sirve de factor pull o efecto llamada (Arango, 1985 ) para la población de los países vecinos, como la República Democrática del Congo, Zambia y Namibia. A estos factores se añade la extensa y vulnerable frontera terrestre del país que sirve de cauce para la migración irregular. De todas formas, la migración irregular es igualmente propiciada por las rígidas normativas migratorias, la falta de estructuras institucionales y el soborno o la corrupción.

Así, la llegada de los inmigrantes es un hecho innegable y los sectores de la construcción, la minería y la empresa son los que más acogen a la población inmigrante. Además de aportar a la economía del país (Ramón, Jesus Fortes, 2009), los migrantes están dando una nueva configuración a la ya rica diversidad cultural. Entretanto, como afirma el representante de la ONU, "o seu estatuto é raramente regularizado e enfrentam condições de exploração do trabalho" (Crépeau, 2016). Esta cita nos sirve de trampolín para hablar de la situación de los derechos humanos de los migrantes en Angola. Con todo, Crépeau comienza por invitar al gobierno angoleño a sumarse a declaraciones y convenciones en las que Angola todavía no ha tomado parte. Esto ayudaría a mejorar la situación de los derechos humanos de los migrantes. Entre estas declaraciones y convenciones figuran: la Convención Internacional sobre la Protección de los Derechos de todos los Trabajadores Migrantes y de sus Familiares, la Convención contra la Tortura y otros Tratos o Penas Crueles, Inhumanas o Degradantes y su protocolo y los tratados de la Organización Internacional del Trabajo. Por último, Crépeau anima a extender la formación sobre los derechos humanos a las personas que trabajan directamente con los inmigrantes.

\section{Derechos humanos de los migrantes}

Angola no posee una ley de extranjería adecuada a que se conforma a la realidad migratoria del país (Carciotto, 2014). Lo que Angola tiene actualmente son regulaciones que determinan la entrada, permanencia y salida de los extranjeros ${ }^{2}$. Por desgracia, estas regulaciones son excesivamente rigurosas y parecen tener como objetivo principal sancionar la migración irregular. De hecho, esto se refleja en el preámbulo de la actual norma de extranjería: "Lei n. ${ }^{\circ}$ 2/07, de 31 de Agosto [...] este diploma tem por objectivo realizar um controlo mais eficaz da imigração ilegal regulando e permitindo a criação de melhores condições para a integração dos imigrantes em território nacional" ${ }^{3}$.

\footnotetext{
2 Ley 2/07, sobre el régimen jurídico de los extranjeros en Angola; Decreto Presidencial 108/2011, que promulga el régimen jurídico de los extranjeros en Angola; el Decreto Presidencial 43/17, que regula el empleo de la fuerza de trabajo extranjera no residente y la Ley 10/15, sobre el derecho de asilo y estatuto de refugiado.

Ley $2 / 07$, Preámbulo.
} 
La integración de los migrantes acaba siendo secundaria, puesto que lo que se pretende es sancionar a los que se hallan en situación irregular. La complejidad actual del fenómeno migratorio empuja al país a elaborar normativas que respondan al momento actual. Tiempo atrás éramos un país de emigración, y seguimos siéndolo en cierta medida, pues el conflicto armado así lo justificaba (Lopes, 2013). Pero no hace más de quince años que nos estamos convirtiendo en una sociedad receptora, es decir, un país de inmigración ${ }^{4}$. Por eso, hace falta elaborar una estrategia global que responda a la coyuntura actual de las migraciones en el país. Esta visión estratégica debería estar basada en la dignidad de la persona humana y en la protección de sus valores fundamentales.

El informe del enviado especial de la ONU así lo constata. Crépeau verificó la existencia de regulaciones duras. Por eso, recomienda que "as autoridades angolanas definam uma estratégia de migração global, que tenha em conta todos os aspectos da migração e que fomente o estatuto regular para a maioria dos migrantes, por meio da organização e facilitação da mobilidade ao invés de tentar resistir a ela" (Crépeau, 2016). La resistencia a la que el observador de la ONU hace referencia tiene que ver con la rigidez de las regulaciones. La consecuencia lógica es la condición irregular de la mayoría de los inmigrantes. La extensa frontera terrestre $(5.198 \mathrm{~km})$ y marítima $(1.600$ $\mathrm{km}$ ), así como la corrupción contribuyen a que la irregularidad gane cuerpo y se convierta en la opción más beneficiosa. Los migrantes con menos suerte son detenidos y cuando eso ocurre, muchos de sus derechos son violados. Entre las recomendaciones de Crépeau se incluyen: primero, despenalizar la migración irregular ya que "não é e nunca deve ser considerada um crime" (Crépeau, 2016); segundo, ratificar el Protocolo Facultativo de la Convención contra la Tortura y realizar visitas regulares a los centros de detención de los migrantes sin previo aviso; y por último, crear una Institución Nacional de los Derechos Humanos independiente asentado en los Principios de Paris del año 1990.

La precariedad económica y social del país hace que haya extorsiones y ocasiones de lucro fácil. No es novedoso que la economía de Angola esté basada en la petrodependencia, ya que el $80 \%$ de sus recursos proviene del petróleo (Centro de Estudo e Investigação Científica da Universidade Católica de Angola, 2010). Por lo que la quiebra del precio del oro negro está afectando al país y entre los sectores que más se resiente con la actual coyuntura económica se encuentra el de la seguridad y de la construcción. Los migrantes sin papeles se han convertido en cajeros bancarios de muchos agentes de seguridad. Redadas, intimidaciones y detenciones arbitrarias son a menudo empleadas para sacar dinero a los indocumentados. Las amenazas de los agentes también son extensivas a los defensores de los derechos de los

4 Una descripción sobre las cifras actuales de las migraciones, en Milagres, Santos, 2013. 
migrantes irregulares. Así como la amenaza de los agentes a los inmigrantes está motivada por la extorsión económica, la manipulación sobre los activistas y los abogados consiste en forzarlos al silencio. En realidad, así ha sido informado Crépeau durante su estancia:

Fui informado de que migrantes em situação irregular, requerentes de asilo e refugiados são com muita frequência alvo de assédio e intimidação por parte da polícia. Fui informado de que a polícia efectua acções nas minas artesanais de diamantes, mercados informais, áreas residenciais, lojas, ruas, igrejas e mesquitas, em busca de imigrantes em situação irregular, indo por vezes de porta em porta. Estas operações são muitas vezes marcadas por violência, ameaças, intimidação e a destruição de documentação de identificação válida. Fui informado de que migrantes e requerentes de asilo são regularmente presos e detidos em grande número, incluindo mulheres grávidas e crianças, e que os policiais usam isso como uma oportunidade para subornar os migrantes indocumentados. Os migrantes indocumentados são então detidos sem acesso à informação jurídica ou assistência. Também recebi informação de que aqueles que defendem os direitos dos migrantes em situação irregular também podem ser intimidados pela polícia. (Crépeau, 2016)

Las informaciones que el supervisor de la ONU ha recibido parecen gravísimas. Algunas necesitan ser averiguadas de inmediato y otras tomadas con cautela. Muchas de estas situaciones siguen ocurriendo. Entre las recomendaciones que Crépeau ha dejado consta la necesidad de confirmar la veracidad de los hechos. Enseguida afirma que no basta con investigar, también es necesario procesar y condenar a los culpables. Éstos, recomienda Crépeau, deberían enfrentarse a sanciones duras y ejemplares. Con todo, ya ha pasado un año desde que el mandatario de la ONU visitó el país y hasta al presente nadie ha sido condenado por ganarse la vida a costa de los migrantes. Lo que se ha verificado y, en esto nos congratulamos con la policía, es la detención de agentes falsos que se acercan con frecuencia a las tiendas de los inmigrantes y refugiados para intimidarles y lograr sacarles algún dinero. Lo mismo sucede con los agentes que cobran sumas abultadas a los extranjeros para expedirles a prisa sus documentos (Costa, 2014).

El derecho de asilo aparece recogido en la constitución del país:

É garantido a todo o cidadão estrangeiro ou apátrida o direito de asilo em caso de perseguição por motivos políticos, nomeadamente de grave ameaça ou de perseguição, em consequência da sua actividade em favor da democracia, da independência nacional, da paz entre os povos, da liberdade e dos direitos da pessoa humana. (Constitución de Angola, art. 71)

Entretanto, para regular el derecho de asilo y recogerlo en una orden jurídica interna $y$, por consiguiente cumplir con sus obligaciones internacionales, el gobierno angoleño aprobó la Ley 8/90, de 26 de mayo, 
inicialmente y actualmente la Ley 10/15, de 17 de junio. Hasta hace poco la Ley $8 / 90$ era la que regulaba el derecho de asilo y el estatuto de los refugiados. Entretanto, el panorama migratorio ha cambiado desde entonces $y$, para responder al actual momento, los legisladores angoleños aprobaron la Ley $10 / 15$.

La Ley $8 / 90$ y la Ley 10/15 tienen en cuenta los presupuestos legales para la concesión de asilo en la República de Angola. No es nuestra pretensión hacer un análisis minucioso de estas leyes y tampoco un estudio comparado de éstos. Apenas señalar los aspectos que el alto mandatario de la ONU ha constatado como innecesariamente rígidas. La primera indagación tiene que ver con el vacío jurídico que la Ley 10/15 ha creado. Dicho de otro modo, después de la derogación de la Ley 8/90 y de la entrada en vigor de la ley 10/15, los procesos de atribución del estatuto de refugiados han quedado atascados. Hace falta crear estructuras institucionales tales como el Consejo Nacional para los Refugiados $(\mathrm{CNR})^{5}$ y los Centros de Acogida de Refugiados y Requirentes de Asilo (CARRA), que se amoldan a la nueva ley. La Ley 10/15 prevé la emisión de nuevos documentos de identificación; sin embargo, la directiva que aprueba la introducción de éstos no está concluida todavía. A esto se añade la suspensión, por parte del Servicio de Migración y Extranjeros (SME), a la emisión de documentos de identificación para los solicitantes que lo han hecho desde la entrada en vigor de la nueva normativa. El derecho de ejercer una actividad laboral no es reconocido en la Ley 10/15, contrariamente a la Ley 8/90, que lo contemplaba. Además, la ley 10/15 parece introducir una política de detención obligatoria, ya que uno de sus objetivos consiste en inhibir "a utilização abusiva do processo de asilo àqueles que, de modo fraudulento, pretendam entrar no país, não satisfazendo nenhuma das condições definidas pelas convenções para beneficiar do estatuto do refugiado" (Ley 10/15, Sumario ).

Por este motivo, contrariamente a lo que se pretendía con la regularización, celeridad y, consecuentemente, armonización de los procesos relativos a la solicitud de asilo en respuesta a la actual coyuntura migratoria del país, la nueva ley sobre el derecho de asilo y el estatuto del refugiado tiene todavía muchas lagunas. Entre éstas, quizá la más grave sea que la Ley 10/15 ha dejado a muchos sin documento de identificación. Esto tiene consecuencias enormes, como el acceso a los servicios públicos (salud y educación) y la detención automática de los solicitantes de asilo y refugiados. Por eso, Crépeau exhorta al gobierno angoleño a "registar todos os requerentes de asilo que vivem em Angola, a concluir e implementar o regulamento relativo à emissão de documentos de identificação de qualidade para os requerentes de

\footnotetext{
5 Órgano de naturaleza multisectorial consultiva competente para apreciar y pronunciarse sobre los procesos de pedido de asilo y pierda del estatuto de refugiado.
} 
asilo e refugiados e a comprometer-se a emitir documentos para os requerentes de asilo e refugiados" (Crépeau, 2016).

Sin embargo, la Ley $10 / 15$ ha supuesto un paso hacia adelante con respecto a la Convención de Ginebra de 1951 y a la Convención Africana de 1969. Los dos documentos no reconocen la atribución del estatuto de refugiado a los que huyen por motivos medioambientales o ecológicos. En cambio, aunque no está siendo aplicada, como hemos dicho en su momento, la norma angoleña recoge las causas ambientales. Dicho con otros términos, el Estado angoleño atribuye el estatuto de refugiados a los individuos que huyen por motivos ecológicos: sequía y catástrofes naturales. Es más, la condición es que procedan de los países vecinos con los que Angola comparte sus fronteras. Es decir, la República Democrática del Congo, la República del Congo, Zambia y Namibia. Más aún, debe tratarse de un grupo de personas, por lo que una persona singular tendría dificultad de acceder al estatuto de refugiado alegando motivos medioambientales o ecológicos. La formulación de la ley parece más clara:

O Estado angolano pode conceder o direito de asilo e o estatuto de refugiado a pessoas, em grupo ou isoladas que saiam do país de origem ou de residência habitual, de fronteira comum com a República de Angola, em consequência de graves conflitos armados, ocupação ou dominação estrangeira do seu território nacional ou calamidades naturais, que originem fluxos de refugiados em larga escala. (Ley 10/15, art. 32.1.)

\section{Detención y expulsión en masa}

La falta de un sistema informático moderno hace que se establezca la detención como prioridad. Además de ser un lugar de espera para la ejecución de la expulsión, los centros de detención se han convertidos en lugares de chequeo de documentos. La detención, resalta el relator de la ONU, "não é uma ferramenta legítima nem uma ferramenta eficaz para dissuadir a migração não documentada e dá origem ao efeito oposto de encaminhá-los ainda mais para a clandestinidade" (Crépeau, 2016). Aparte de la falta de acceso a la justicia, lo más llamativo es que entre los detenidos se encuentran mujeres con sus niños. Todavía más, los niños más crecidos de sexo masculino son mantenidos con los adultos. Angola ha firmado la Convención sobre los Derechos del Niño y Crépeau recuerda que

o princípio do superior interesse da criança deve sempre orientar todas as decisões referentes às crianças, independentemente da sua situação administrativa e circunstâncias. A detenção nunca pode ser no melhor interesse de uma criança, e as crianças nunca devem ser detidas por razões relacionadas com a sua situação migratória ou a de seus pais, nem famílias com crianças. (Crépeau, 2016) 
Los dos grandes centros de detención de extranjeros, el de Cabinda y el de Luanda (Trinta), fueron visitados por el supervisor de la ONU. Estos centros, particularmente el Trinta tiene la capacidad de acoger a más de quinientos migrantes. Para sorpresa de todos, mientras que en el centro de Cabinda Crépeau no halló a ningún migrante, en el de Trinta sólo encontró a cinco. Los números de migrantes que pasan por estos centros son abrumadores, por eso nos extraña, pero no nos sorprende, que no se haya encontrado allí más que un puñado de migrantes. Por ejemplo, en el balance del segundo cuadrimestre del año 2014, Simão Milagres, el entonces portavoz del Servicio de Migración y Extranjeros (SME) y actual responsable de comunicación institucional y de prensa del Ministerio del Interior, afirma que "sem contarmos com os três últimos meses do último trimestre andamos a volta de 38 mil e quinhentas expulsões de imigrantes ilegais" (O país, 2014). Pasados tres años, la realidad no ha cambiado del todo y los migrantes siguen viniendo a Angola. Por eso, lo más probable es que se haya dado otro tratamiento o solución express a los migrantes que se encontraban en los centros de detención durante la visita de Crépeau. En ella podría constar la deportación en masa, que el observador de la ONU criticó severamente.

Tabla 1. Evolución de las deportaciones de los inmigrantes en Angola

\begin{tabular}{c|c}
\hline Año & Número \\
\hline 2005 & 7.340 \\
\hline 2006 & 15.617 \\
\hline 2007 & 30.439 \\
\hline 2008 & 17.058 \\
\hline 2009 & 46.617 \\
\hline 2010 & 15.667 \\
\hline 2011 & 38.277 \\
\hline 2012 & 37.728 \\
\hline 2013 & 33.707 \\
\hline 2014 & 50.726 \\
\hline 2015 & 40.780 \\
\hline 2016 & 81.904 \\
\hline
\end{tabular}

Fuente: elaboración propia a partir de Milagres (2018).

El número tan exiguo de migrantes que Crépeau halló en los centros de detención nos hace creer que su visita fue poco productiva. Con todo, la efectividad no tiene que ver solamente con la catadura, sino también con la información que logró de los pocos con que se había encontrado. De hecho, el valor de la información del enviado de la ONU reside en las 
duras condiciones de detención, sobre todo la de la sobrecarga o saturación. También en la poca privacidad de los detenidos y en la detención por tiempo indeterminado. En muchas ocasiones, la detención sólo terminaba con la expulsión, el chequeo de los documentos o el pago del soborno. Finalmente, el enviado de la ONU constató que la expulsión en masa o "expulsión en caliente" ${ }^{16}$ es una práctica que ocurre con frecuencia en los puestos fronterizos con la República Democrática del Congo. Eso constituye una clara violación del principio de non refoulement de la Convención de Ginebra (art. 33) y de la Ley 10/15 sobre el estatuto de refugiado en Angola (Ley 10/15, art. 3 \& 54). Así, la recomendación de Crépeau consiste en la creación de mecanismos que permitan el cumplimiento del principio de no devolución. De la misma manera, recomienda que la detención sea el último recurso y con una duración mínima.

Los inmigrantes y refugiados también sufren a la hora de acceder a determinados servicios básicos, como educación, salud y vivienda. En mayo de 2011, el Ministerio de la Justicia y de los Derechos Humanos de Angola hizo salir una Circular de Ejecución Permanente que prohibía la inscripción de nacimiento de niños de padres extranjeros, incluso los refugiados ${ }^{7}$. En el momento en que Crépeau visitaba Angola y hasta a la fecha, la Circular no ha sido revocada. Como consecuencia, aunque no haya estudios sobre el tema, se corre el riesgo de tener a niños apátridas. Con todo, se presionó al gobierno angoleño y algunos niños empezaron a ser registrados. Pero la situación no ha cambiado mucho, puesto que los pocos que han sido registrados, constan en sus documentos como hijos de padres extranjeros. En efecto, la dificultad de acceso a los servicios públicos nace de esa cláusula discriminatoria.

El representante de la ONU escuchó a los migrantes cuyos hijos se vieran afectados por la directiva del Ministerio de la Justicia y de los Derechos Humanos. De igual modo, se acercó a las organizaciones involucradas en la revocación de la instrucción administrativa. Tras esto, exhortó a las

autoridades a ampliar a campanha de registo de nascimento gratuito para abranger todos os estrangeiros nascidos em Angola, incluindo os migrantes sem documentos e refugiados, a fim de garantir que eles têm garantido o acesso aos direitos económicos, sociais e culturais sem discriminação. Eu incito Angola a tomar todas as medidas adequadas e eficazes para combater e eliminar a discriminação contra os migrantes e combater percepções negativas dos migrantes. (Crépeau, 2016)

\footnotetext{
6 Se trata de la expulsión llevada a cabo al margen de la ley. Para una comprensión más detallada, en Martínez Escamilla et alii (2016). “'Expulsiones en caliente': cuando el Estado actúa al margen de la ley".

7 Para acceder a la Circular: <http://www.cidadao.gov.ao/VerPublicacao.aspx?id=783>.
} 


\section{Valoración}

El informe es bastante directo a la hora de señalar y apuntar a los hechos. El lenguaje empleado es igualmente accesible y adaptado a la realidad planteada. En este sentido tiene un valor positivo pues es muy informativo y no deja a nadie de fuera. El haber estado y reunido con las autoridades y entidades de la sociedad civil y con los propios migrantes hace que el informe tenga una visión amplia. Lo mismo sucede con las visitas que el observador hizo en los dos centros de detención de migrantes, el de Cabinda y el de Luanda (Trinta). No obstante, creemos que no hacía falta una extrapolación para que se sepa que los derechos humanos de los migrantes constituye un desafío enorme para las autoridades políticas. Si los países de larga tradición democrática no lo tienen del todo fácil, no constituye una sorpresa que Angola lo tenga todavía más difícil. Eso no reduce el interés que los angoleños tienen en mejorar la cuestión de los derechos humanos de los migrantes. De hecho, la solicitud de un alto mandatario de la ONU muestra que el país pretende mejorar la cultura del respeto de los derechos humanos y acogida de refugiados, inmigrantes y otros individuos en situación de movilidad y fragilidad. Asimismo, busca profundizar su cultura democrática y estado de derecho.

Los derechos humanos son herramientas para la protección de la dignidad humana y el contexto de la Declaración Universal de los Derechos Humanos de 1948 así lo atestigua. Las dos grandes guerras mundiales habían producido gran cantidad de víctimas mortales y destruido una parte significativa del tejido humano. De esa manera, hacía falta una voz con autoridad que pusiera fin a las barbaridades perpetradas contra la dignidad humana; la Declaración nace para ser esta voz (Lucas Martin et alii, 2008). Sin embargo, no es la Declaración la que otorga esta dignidad, aunque esté recogida en las legislaciones internas. Dicho con otras palabras,

Los derechos humanos no dejan de ser derechos aunque el Derecho positivo los ignore o los viole. Es cierto que los derechos humanos están mejor protegidos (y más efectivamente) allí donde se reconocen jurídicamente, pero esos derechos humanos transcienden planteamientos meramente legalistas. (Arroyo Velasco, 1990)

El informe plantea dos modalidades de lenguaje, el de la constatación de los acontecimientos y el de la recomendación. El primero tiene que ver con la preocupación que Crépeau tiene sobre la creación de una institución nacional independiente que salvaguarde los derechos humanos de los migrantes. A pesar de que ya existe dentro del Ministerio de Justicia un departamento que tutela los derechos humanos, no es casualidad que el enviado especial de la ONU hiciera esta salvedad pues existe un vacío. Tenemos organizaciones de la sociedad civil involucrados en estos temas, sobre todo el Mosaico-Instituto 
para la Ciudadanía ${ }^{8}$. Pero los casos de violación de los derechos humanos demandan la existencia de más organismos que ofrezcan cauces adecuados para la protección y respecto de los derechos de todos. Además, al ser una entidad gubernamental, el Ministerio de la Justicia y de los Derechos Humanos presenta límites que sólo una institución independiente puede suplir. Entre estos límites destaca la cuestión de la neutralidad y la poca confianza que los organismos gubernamentales ofrecen a los ciudadanos, tanto nacionales como extranjeros.

El segundo aspecto que el informe despliega tiene que ver con la osadía. Con esto queremos expresar su valentía a la hora de decir las cosas, indicar dónde se encuentran las heridas y cómo sanarlas. Decir que las redadas de los indocumentados, así como su detención e intimidación son utilizadas por las fuerzas de seguridad para sacarles algunos Kwanzas ${ }^{9}$ requiere una cierta valentía. Lo mismo se podría decir al poner de relieve la violación del derecho de movilidad de los migrantes. En realidad, estos relatos no son del todo desconocidos entre las instituciones que trabajan con los migrantes. La nota positiva del informe surge por el hecho de ser contundente a la hora señalar los acontecimientos. Por ejemplo, el informe explicita que hay miembros de la sociedad civil que intentan defender los derechos de los migrantes que son con frecuencia amenazados. Esta reflexión nos permite abogar por la definición de una política migratoria que propicie la creación de canales oficiales de regularización de los indocumentados. El informe surge como una especie de impulso no solamente para empezar a reflexionar con detenimiento sobre las múltiples quejas de violación de los derechos humanos de los migrantes en Angola, sino para poner en marcha leyes de extranjería que respeten la dignidad de todos.

\section{Situación migratoria de Angola y sus desafíos}

La manera más sensata de comprender el tono y el lenguaje del informe consiste en echar una mirada hacia la historia migratoria del país, así como la de los derechos humanos. No hace mucho, y aunque todavía sigue siendo así, Angola fue un país de emigración. Además de la quiebra de la economía, deterioro social y ausencia de bienestar, corrupción, mala gestión de los recursos de que dispone el país, la guerra que asoló el país en los últimos cuarenta años fue el principal detonante de la salida de los angoleños. Sus destinos más destacados eran Portugal, Zambia, Namibia, Congo, Alemania, Francia, Reino Unido, Brasil, España, EE.UU., Canadá y Bélgica (Tinajero, 2010). Entre estos países, Congo y Portugal fueron los principales hogares de los angoleños.

\footnotetext{
8 Se trata de una de las primeras institución fundada por los dominicos cuya misión consiste en la defensa y promoción de los derechos humanos.

9 Moneda angoleña.
} 
En caso de Portugal, aparte del pasado colonial, cabe resaltar las afinidades culturales y la lengua, que jugaron y siempre jugarán un rol importante a la hora de elegir este país como destino. Se estima que Portugal acogía el 30\% de los emigrantes angoleños (Serviço de Estrangeiros e Fronteiras, 2001). A esto se suma el número alarmante de refugiados, que hasta 2002 era estimado en 1.7 millones (Carciotto, 2014), así como desplazados internos, que rondaba los 5 millones (Soares, 2015).

En este periodo del conflicto armado aún era impensable hablar de los derechos humanos. Los dos movimientos que se perfilaban en el escenario de la guerra no respetaban los derechos humanos tanto de la población nacional como de los pocos refugiados e inmigrantes que el país acogía. En las zonas controladas por el MPLA (Movimiento Popular de Liberación de Angola), que fueron esencialmente las ciudades, los derechos económicos, culturales y sociales de la población nacional y extranjera no eran tomados en cuenta (Oliveira, 2015). La falta de bienestar, el hambre que sacudía las principales ciudades del país, la degradación económica, la existencia de niños fuera del sistema de educación son apenas algunos ejemplos. Desde el punto de vista migratorio fue notoria la tardía adhesión del país en los pactos internacionales. Angola se independiza del régimen colonial portugués en 1975 pero ratifica la Convención de Ginebra y la Convención Africana en 1981. Más aún, la primera ley sobre el estatuto de refugiados fue aprobada casi diez años más tarde, es decir, en 1990 (Ley 8/90 de 26 de mayo). Por ejemplo, los refugiados Katangueses oriundos de la República Democrática del Congo que el país acogía en la época no sólo vieron muchos de sus derechos violados, sino que la mayoría no poseía ni carnés de refugiados ni carnés de solicitantes de asilo (Nzatuzola, 1997).

En los bastiones controlados por UNITA (Unión Nacional por la Independencia Total de Angola), la situación no era distinta. Se oían relatos de prisiones arbitrarias, falta de libertad de movimiento y expresión, así como muertes de personas que desafiaban los líderes del movimiento (Muekalia, 2015). Más aún, en plena guerrilla y lucha por la democracia el tema de los derechos humanos queda de lejos. Aunque no eran propiamente ni inmigrantes ni refugiados, varios extranjeros al servicio de organizaciones humanitarias como la Cruz Roja fueron arrestados, secuestrados y muertos durante el conflicto. Asimismo, hay que añadir misioneros que sufrieron las mismas atrocidades. Con todo, el discurso sobre los derechos humanos empieza a entrar en la agenda política del gobierno tras la guerra.

En 1991 se firman los acuerdos de paz de Bicesse (Portugal) que abre el camino hacia el sistema multipartidista. En este mismo año se inaugura en Luanda la oficina de las Naciones Unidas (MONUA) encargada de averiguar la puesta en marcha de los acuerdos de paz. La MONUA poseía una repartición de 
derechos humanos y clamaba por los derechos fundamentales de los refugiados, los retornados, los desplazados internos y las víctimas del conflicto. Las primeras organizaciones de la sociedad civil defensoras de los derechos humanos irrumpen esta época. En 1990 nace ADRA (Acção para o Desenvolvimento Rural e Ambiente), en 1997 Mosaiko: Instituto por la Ciudadanía e en 2000 Associação Mãos Livres. Esta apertura se consolida en 2008 tras las segundas elecciones generales del país. Es decir, el gobierno crea la Secretaría de Estado de Derechos Humanos. El secretario despacha directamente al Presidente de la República. Sin embargo, en 2012 se pone fin al privilegio que gozaba el secretario. La Secretaría se funde con el Ministerio de Justica que pasa a denominarse Ministerio de Justicia y Derechos Humanos. La manera como el país era visto en el escenario mundial forzó al gobierno crear el ambiente que propiciara el respeto a los derechos humanos (Montes, 2002).

El final de la guerra ha traído cambios significativos en el mapa migratorio del país: de país de emigración (emisor de migrantes), Angola se fue convirtiendo en país de inmigración (receptor de migrantes). Pese a la crisis económica y financiera que el país afronta desde 2014, Angola continúa siendo emisor de remesas. Su posición geográfica, el desarrollo económico, la existencia de recursos naturales, los sueldos altos y la necesidad de mano de obra extranjera han servido de catalizador para atraer a muchos migrantes de países vecinos, asiáticos, europeos y latinos. La mayoría de estos inmigrantes son jóvenes y su perfil académico abarca distintos niveles de cualificación. Hay los altamente cualificados pero también se encuentra los iletrados y los carentes de escolaridad. Algunos vienen con sus familias, mujeres e hijos; otros lo hacen sólo. Muchos se hallan en el sector de la construcción, comercio, industria, telecomunicación, marketing, agricultura, educación, sanidad, pesca y minería. Carlos, un joven médico peruano, cuenta en pocas líneas las razones que le llevaron a venir a Angola:

Emigrar es una buena forma de avanzar en mi profesión. Quiero permanecer en Luanda porque mi trabajo conlleva una serie de responsabilidades y mi sueldo es mucho más elevado del que ganaría en Perú realizando el mismo trabajo. Eso me permite tener una vida cómoda y enviar dinero periódicamente a mi familia. (OIM, 2014)

Tabla 2. Remesas de migrantes enviadas y recibidas por Angola

\begin{tabular}{c|c|c|c|c|c|c}
\hline & $\mathbf{2 0 1 0}$ & $\mathbf{2 0 1 1}$ & $\mathbf{2 0 1 2}$ & $\mathbf{2 0 1 3}$ & $\mathbf{2 0 1 4}$ & $\mathbf{2 0 1 5}$ \\
\hline Remesas enviadas (US\$ millón) & 38,9 & 43,4 & 43,7 & 44,9 & 44,7 & 43,1 \\
\hline Remesas enviadas (\%PIB) & $0,05 \%$ & $0,04 \%$ & $0,04 \%$ & $0,04 \%$ & $0,04 \%$ & $0,04 \%$ \\
\hline Remesas recibidas (US\$ millón) & 18,0 & 0,2 & 0,2 & 0,0 & 11,1 & 11,1 \\
\hline Remesas recibidas (\%PIB) & $0,02 \%$ & $0 \%$ & $0 \%$ & $0 \%$ & $0,01 \%$ & $0,01 \%$ \\
\hline
\end{tabular}

Fuente: Elaboración propia a partir de World Bank (2016). 
A pesar de la crisis económica, los migrantes que se encuentran en Angola no se están marchando. Algunas empresas cerraron pero las oportunidades siguen en abierto $y$, por consiguiente, atrayendo a inmigrantes e inversores de varios rincones del mundo. De esa manera, en vez de bajar, la migración neta va subiendo. Hasta el año pasado, es decir, en 2017, el país acogía 638.500 inmigrantes. La cifra corresponde al $2.1 \%$ de la población (IOM, 2018). En enero 2018 Angola acogía, asimismo, 95.600 refugiados y 30.143 solicitantes de asilo (UNHCR, 2018). Con todo, estos datos no contemplan los inmigrantes en situación irregular. Es más, se hace poco para la integración de los inmigrantes. La prueba de esto es que todavía no existe una ley de inmigración. El primer síntoma que muestra que hacemos muy poco en favor de la integración de los migrantes, particularmente los solicitantes de asilo y refugiados, se observa en el fenómeno de la dependencia que intentamos instituir. El derecho al trabajo no es reconocido en los demandantes de asilo. Los refugiados también se encuentran en la misma situación. En agosto de 2013, el gobierno aprobó el reglamento 273/13, en el cual se prohíbe a los solicitantes de asilo y refugiados el derecho de obtener la licencia de apertura y actividad.

Un segundo problema es que el país no posee ni un modelo de integración ni una ley de inmigración. Existen normas sobre la selección, entrada, permanencia y salida de los extranjeros. En concreto, la Ley 2/07, sobre el Régimen Jurídico de los Extranjeros en Angola, y el Decreto Presidencial 108/11, que promulga dicha ley. Pero también existe la Ley 10/15 que regula el derecho de asilo. La Ley 2/16, sobre la nacionalidad, es otra disposición legal muy controvertida. Finalmente, se perfila la Ley 7/15, Ley General del Trabajo, que también regula la actividad laboral de los extranjeros residentes y el Decreto Presidencial 43/17 que regula la actividad profesional de los trabajadores extranjeros no residentes. Estas leyes imponen una serie de restricciones en materia de acceso al trabajo, derechos políticos y de movilidad que nos lleva a concluir que el país tiene una visión miope de las migraciones y su relación con el desarrollo (Guadamillas, 2017).

Por ejemplo, la Ley 2/07 empieza por establecer el principio de equiparación entre el ciudadano nacional y el extranjero (art.3). También otorga el derecho a ejercer un oficio predominantemente técnico, docente o investigador (art.4). Otros derechos son los de libre circulación, elección de vivienda, reunión, manifestación (art.6), educación y enseñanza (art.7), recurso a los órganos judiciales (art.11) y reagrupación familiar (art.91). Sin embargo, el extranjero no puede ejercer ningún cargo en el sector público (art.4). Tampoco puede inmiscuirse de manera directa o indirecta en los asuntos políticos del país (art.10). De igual modo se le prohíbe promover o auxiliar la entrada ilegal de migrantes (art.113) y emplear mano de obra ilegal 
(art.114). Nos llama la atención el derecho a la reagrupación familiar, que es una medida positiva pues que podría favorecer la entrada e integración de los migrantes. No obstante, al mismo tiempo, despierta nuestra curiosidad el hecho de que se prohíba el disfrute de actividades económicas remunerables en el sector público. Eso indica que el sector privado e informal es la única puerta abierta a los extranjeros para su supervivencia.

\section{Conclusión}

A lo largo de este trabajo hemos examinado las líneas maestras del informe del enviado especial de la ONU sobre los derechos humanos de los migrantes en Angola. Tras señalar la existencia de violación de los derechos fundamentales de este colectivo, nos dedicamos a enumerarlas. Los migrantes sufren a menudo intimidación y asedio por parte de las autoridades. Se efectúan redadas en los puntos focales, como en los mercados, iglesias, mezquitas, zonas residenciales, calles y minas de diamantes de Lunda Norte y Lunda Sul. Además de adultos, las detenciones se extienden a los menores. La falta de un sistema informático avanzado hace que se emplee la detención como recurso de primer orden. Como consecuencia, se asiste a la expulsión en masa, la práctica del soborno ${ }^{10}$ y el recurso a la clandestinidad. Muchas de estas acciones ocurren violando la dignidad de los migrantes. Sería recomendable la creación de una comisión nacional independiente para los derechos humanos. Asimismo sería conveniente la creación de corredores legales para la migración, aparte de los tradicionales. Hace falta promover comunidades regionales visa-free, a ejemplo de lo que ya disfrutan los ciudadanos de la Comunidad Económica de Estados del África Occidental (CEDEAO). En realidad, lo que nos une es más fundamental que lo que nos diferencia (Wiredu, 1998).

\section{Referencias}

ADEPOJU, Aderanti. Creating a Borderless West Africa: Constraints and Prospects for Intra-Regional Migration. In: PÉCOUD, Antoine; GUCHTENEIRE, Paul (eds.). Migration without Borders: Essay on the Free Movement of People. New York: Berghahn, 2007, p. 161-174.

ARANGO, Joaquín. Las 'leyes de las migraciones' de EG Ravenstein, cien años después". Reis, n. 32, p. 7-26, 1985.

ARROYO VELASCO, Juan Carlos. Aproximación al concepto de los derechos humanos. Anuario de Derechos Humanos, v. 7, p. 269-284, 1990.

\footnotetext{
${ }^{10}$ Los migrantes que tienen el soborno como forma de arraigo terminan permaneciendo en el país por largo periodo de tiempo.
} 
CARCIOTTO, Sergio. Human Mobility in Angola. In: BAGGIO, Fabio (ed.). Africans on the Move: Human Mobility in Ghana, Nigeria, Angola and South Africa. Cape Town: Scalabrini Institute for Humans Mobility in Africa, 2014, p. 117-159.

Centro de Estudo e Investigação Científica da Universidade Católica de Angola. Relatório económico anual de Angola 2009. 2010. Disponible en: < http://www. ceic-ucan.org/wp-content/uploads/2013/12/relatorioeconomico2009.pdf $>$. Acceso en: 04.06.2018.

COSTA, André. Oficiais do SME foram expulsos. Jornal de Angola. 2014. Disponible en: <http://jornaldeangola.sapo.ao/sociedade/oficiais_do_sme_foram_expulsos > . Acceso en: 04.06.2018.

CRÉPEAU, François. Relatório sobre os direitos humanos dos migrantes en Angola. 2016. Disponible en: <http://www.pordentrodaafrica.com/wp-content/uploads/ kalins-pdf/singles/angola-especialista-da-onu-pede-estrategia-inclusiva-paramigrantes.pdf>. Acceso en: 04.06.2018.

GUADAMILLAS, Francisco. Europa: entre el miedo y la hospitalidad. Santander: Editorial Sal Terrae, 2017.

IOM. Key Migration Statistics. 2018. Disponible en: < https://migrationdataportal. org/?i=stock_abs_\&t=2017\&cm49=24>. Acceso en: 04.06.2018.

LOPES, Carlos. Reforçar a gestão de dados sobre as migrações em Angola: avaliação e recomendações. 2013. Disponible en: < http://publications.iom.int/system/ files/pdf/angola.pdf>. Acceso en: 04.06.2018.

LUCAS MARTÍN, Javier de et alii. Los derechos de participación como elemento de integración de los inmigrantes. Bilbao: Rubes Editorial, 2008.

MARTÍNEZ ESCAMILLA, Margarita et alii. 'Expulsiones en caliente': cuando el Estado actúa al margen de la ley. 2016. Disponible en: < http://eprints.ucm. es/25993/1/INFORME\%20\%20EXPULSIONES\%20EN\%20CALIENTE.\%20 27 6_2014\%20\%281\%29.pdf>. Acceso en: 04.06.2018.

MILAGRES, Simão; SANTOS, Lutina. Fluxos migratórios em Angola. Luanda: Mayamba Editora, 2013.

MILAGRES, Simão; SANTOS, Lutina. Fluxos migratórios em Angola: novos contextos e desafios. Luanda: Mayamba Editora, 2018.

MONTES, Lucía. Angola, un país aplazado. Nova África, n. 10, p. 79-90, 2002.

MUEKALIA, Jardo. Angola - a segunda revolução: memórias da luta pela democracia. Rio de Janeiro: Sextante Editora, 2015.

NZATUZOLA, João. Aspectos de algumas características e manifestações de migrações em Luanda. Africana, n. 18, p. 105-125, 1997.

OIM. Informe sobre las migraciones en el mundo 2013. 2014. Disponible en: $<$ http://publications.iom.int/system/files/pdf/wmr2013_sp.pdf>. Acceso en: 04.06.18.

OLIVEIRA, Ricardo de. Magnífica e miserável: Angola desde a guerra civil. Lisboa: Tinta da China, 2015. 
O País. Expulsos mais de 38 mil estrangeiros em 2014. 2014. Disponible en: $<$ http://opais.co.ao/expulsos-mais-de-38-mil-estrangeiros-em-2014/>. Acceso en: 04.06.2018.

PARK, Yoon Jung. Chinese Migration in Africa. South Africa Institute of International Affairs, Occasional Papers, v. 24, p. 1-17, 2009.

RAMÓN, Montserrat Casanovas; JESUS FORTES, Armanda de Fátima. El sistema financiero de Angola y estrategias de futuro. Investigaciones Europeas de Dirección y Economía de la Empresa, v. 3, n. 15, p. 187-200, 2009.

Serviço de Estrangeiros e Fronteiras. Relatório estatístico 2000. 2001. Disponible en: < http://sefstat.sef.pt/Docs/Rifa_2000.pdf>. Acceso en: 04.06.2018.

SOARES, Alfredo dos Santos. Migrantes forzosos: contextos y desafíos de 'responsabilidad de proteger' en el siglo XXI. Madrid: Universidad Pontificia Comillas, 2015.

TINAJERO, Sandra Paola. Angola: A Study of the Impact of Remittances from Portugal and South Africa. Geneva: IOM, 2010.

UNHCR. Angola. 2018. Disponible en: < http://reporting.unhcr.org/node/10321>. Acceso en: 04.06.2018.

WIREDU, Kwasi. Are the Cultural Universals? In: COETZEE, Pieter; ROUX, Abraham (eds.). The African Philosophy Reader. London: Routledge, 1998, p. 31-40.

WORLD BANK. Migration and Remittances: Factbooks 2016. 2016. Disponible en: $<$ https://openknowledge.worldbank.org/bitstream/handle/10986/23743/9781 46483192. pdf? sequence $=3$ \&isAllowed $=y>$. Acceso en: 21.09.2018.

Recibido para publicación en 11.06.2018

Aceptado para publicación en 26.09.2018

Received for publication in June $11^{\text {th }}, 2018$

Accepted for publication in September $26^{\text {th }}, 2018$

ISSN impresso 1980-8585

ISSN eletrônico 2237-9843

http://dx.doi.org/10.1590/1980-85852503880005405 